\title{
BMJ Material, psychosocial and behavioural Open factors associated with self-reported health in the Republic of Ireland: cross-sectional results from the SLÁN survey
}

\author{
Isabelle Niedhammer, ${ }^{1,2,3,4}$ Sarra Kerrad, ${ }^{1,2,3,4}$ Stefanie Schütte, ${ }^{1,2,3,4}$ \\ Jean-François Chastang, ${ }^{1,2,3}$ Cecily C Kelleher ${ }^{4}$
}

To cite: Niedhammer I, Kerrad S, Schütte S et al. Material, psychosocial and behavioural factors associated with self-reported health in the Republic of Ireland: cross-sectional results from the SLÁN survey. BMJ Open 2013;3:e002797. doi:10.1136/bmjopen-2013002797

- Prepublication history and additional material for this paper are available online. To view these files please visit the journal online (http://dx.doi.org/10.1136/ bmjopen-2013-002797)

Received 26 February 2013 Revised 11 April 2013 Accepted 23 April 2013

This final article is available for use under the terms of the Creative Commons Attribution Non-Commercial 2.0 Licence; see http://bmjopen.bmj.com

For numbered affiliations see end of article.

\section{Correspondence to} Dr Isabelle Niedhammer; isabelle.niedhammer@inserm. $\mathrm{fr}$

\section{ABSTRACT}

Objectives: To explore the associations between various material, psychosocial and behavioural factors and self-reported health (SRH), and to determine whether these associations varied according to educational level.

Design: Representative national cross-sectional survey. Setting: Republic of Ireland.

Participants: 4369 men and 5995 women aged 18 or more (Survey of Lifestyle, Attitudes and Nutrition (SLÁN) 2007).

Methods: SRH was measured using one single item.

Three groups of factors were studied: material, psychosocial and behavioural factors. Statistical analyses were performed using logistic regression analysis and interaction testing, the sample design being taken into account. All results were adjusted for age and educational level and stratified on gender.

Results: When each group of factors was studied separately, non-working status, no private health insurance, inability to afford enough food, no car, being non-married, low social participation, serious neighbourhood problems, low social support, smoking, no alcohol consumption, illicit drug use, low physical activity and obesity were associated with poor SRH. When studied together, some material and psychosocial factors were no longer significant. Four significant interaction terms were found, suggesting that some factors might have a stronger association with SRH among low-educated people.

Conclusions: Various types of factors were found to be associated with SRH, and most of these associations were similar according to educational level. Behavioural factors might be intermediate factors in the causal pathways from material and psychosocial factors to SRH. Prevention policies should integrate a large number of factors comprehensively to improve SRH.

\section{INTRODUCTION}

Self-reported health (SRH) has been studied intensively over the last two decades. This

\section{ARTICLE SUMMARY}

Article focus

- Few studies have investigated a large number of factors in association with self-reported health.

- We assess the associations between a large range of material, psychosocial and behavioural factors and self-reported health, and explore whether these associations varied according to educational level.

Key messages

- Various material, psychosocial and behavioural factors were associated with self-reported health.

- Most of these associations were found to be similar according to educational level. However, four factors were found to have a stronger association with self-reported health among loweducated people.

Strengths and limitations of this study

- The study uses a large nationally representative sample, covers a large number of factors exploring material, psychosocial and behavioural aspects, and is based on structured multivariate analyses and formal interaction testing.

- As the study is cross-sectional, no causal conclusions can be drawn, and no information is available on the duration of exposure to the factors considered.

parameter has several advantages for epidemiological research. It constitutes a general single-item question to which the answers can easily be collected via a selfadministered or administered questionnaire. It reflects a person's integrated perception of health and is known to take into account the various aspects of health, as suggested by WHO's definition of health, which includes its physical, mental and social aspects. Several authors have reported strong 
associations between SRH and more objective measures of morbidity. ${ }^{1-3}$ Further, in prospective studies, poor SRH was found to be a significant predictor of mortality. ${ }^{1}{ }^{2-6}$ In this study, SRH was used as a general health status marker.

Studies have explored the potential risk factors for poor SRH, and have covered various factors of different nature, such as demographic, educational, social, financial, geographical and behavioural factors. ${ }^{7}$ However, each individual study may cover a small number of factors (a median of 7 factors considered per study with multivariate models according to Mantzavinis $e t a l^{2}$ ) and the authors of this review suggest that forthcoming studies should cover a large number of important factors comprehensively, use a large sample size, and adopt adequate multivariate modelling.

Differences in the risk factors of SRH have been observed according to gender or age, suggesting that some factors may be more pertinent in certain age groups or for one gender. ${ }^{8}$ Although there is a strong association between social position and SRH (the lower the social group, the higher the prevalence of poor SRH) ${ }^{10-13}$ the differences in the risk factors of SRH according to social position have been understudied.

Our study is thus an attempt to fill the gap in the knowledge of the factors associated with SRH, by exploring different types of material, psychosocial and behavioural factors, using a large sample size of a national general population, and exploring the differences in the factors associated with SRH according to educational groups, using adequate multivariate analysis including interaction testing.

The objectives of this study were to explore the associations between a large number of material, psychosocial and behavioural factors and SRH in the national population of the Republic of Ireland. An additional objective was to determine whether these associations differed according to educational level.

\section{METHODS}

Population

The study was based on the data from the Survey of Lifestyle, Attitudes and Nutrition (SLÁN) 2007, which is the third SLÁN in Ireland. Commissioned by the Department of Health and Children, this periodical national cross-sectional survey covers questions regarding health, health behaviours, demographic factors and various aspects of living conditions of respondents. The 2007 survey comprised face-to-face interviews of 10364 adults, 4369 men and 5995 women (aged 18 years or more) in private households in the Republic of Ireland and the response rate was $62 \%$. The sampling and weighting of this survey were performed to make it representative of the national Irish population. The GeoDirectory, an anonymous list of all addresses in the Republic of Ireland, was used as the sampling frame. The sample used was probabilistic and was selected using the Economic and Social Research Institute's (ESRI's) RANSAM program. RANSAM is a process for selecting samples in three stages. The first stage involved making a random selection of sampling points based on aggregates of townlands, using a minimum population criterion. These form the primary sampling units (PSUs) or clusters. Following a sort by area characteristics and region, 400 PSUs were systematically selected using a random starting point. Once the required number of PSUs had been selected, a systematic sample of addresses was drawn from within each, again using a random starting point. This resulted in 46 selected addresses per cluster. The third stage involved selecting a respondent at each address. Respondent selection within a household involved implementing a simple randomisation procedure, the so-called next birthday rule. The weighting compensated for any imbalances in the distribution of characteristics in the completed survey sample compared with the population of interest, whether such imbalances occur because of sampling error, from the nature of the sampling frame used, or due to differential response rates within population subgroups. Weighting was a two-stage process: (1) construction of a design weight to compensate for the over-representation of individuals in smaller households (a consequence of the sampling frame used) and (2) calibration of the sample distribution to population totals along a number of dimensions related to gender, age, marital status, economic status, level of education, occupational category, ethnicity, household size and geographical region. Details of the method of sampling are available in the SLÁN 2007 main report. ${ }^{14}$ The survey protocol received ethical approval from the Research Ethics Committee of the Royal College of Surgeons in Ireland (RCSI). Study interviews were conducted by a team of trained survey interviewers, coordinated by ESRI. A previous study has already been published by our team on mental health using these data. ${ }^{15}$

\section{Self-reported health}

SRH was measured using the following question: 'In general would you say your health is...?' There were five response categories: 'excellent', 'very good', 'good', 'fair' and 'poor'. The categories 'excellent', 'very good' and 'good' were used to define good SRH and the categories 'fair' and 'poor' were used to define non-good SRH, named poor SRH in the text.

\section{Potential risk factors of SRH}

The selection of the potential risk factors of SRH has been based on both the literature on risk factors of $\mathrm{SRH}^{7}$ and assumptions, suggesting that some variables may be worth studying (teeth brushing, eg, as poor dental hygiene may be a risk factor for health outcomes). ${ }^{16}$ Three groups of potential risk factors were studied: material, psychosocial and behavioural factors. This classification of factors is inspired from other studies. ${ }^{15}{ }^{17-19}$ Material factors were: work status 
(ie, working or not), absence of private health insurance, insufficient food budget, living in a rented home, absence of telephone and absence of car. Psychosocial factors were: marital status, social support (Oslo scale, including 3 items on the number of close people, friendly interest, and practical help, with scores in the range 3-8 indicating low support, 9-11 moderate support and 12-14 high support ${ }^{20}$ ), formal social participation (at least 1 participation of 7 possibilities: sports clubs, political parties, church groups, social clubs, etc) and neighbourhood/area big problems (at least 1 big problem of 9 possibilities: vandalism, insults, poor public transport, etc). Behavioural factors were: smoking habits, alcohol consumption, that is, calculated as the number of standard units consumed in the previous 7 days, binge drinking or frequency of consumption of six standard drinks or more on one occasion once a week or more, consumption of cannabis and other drugs (cocaine, heroin, ecstasy, etc) within the last year, physical activity (International Physical Activity Questionnaire (IPAQ) questionnaire, http://www.ipaq. ki.se), body mass index (BMI, classified as normal or underweight $<25 \mathrm{~kg} / \mathrm{m}^{2}$, overweight 25 to $<30 \mathrm{~kg} / \mathrm{m}^{2}$ or obese $\geq 30 \mathrm{~kg} / \mathrm{m}^{2}$ ) and teeth brushing less than twice a day. Most items of the questionnaire were selected from national and international survey questionnaires: Centers for Disease Control and Prevention (CDC)-Behavioral Risk Factor Surveillance System (BRFSS), College Lifestyle and Attitudinal National (CLAN) Survey, European Comparative Alcohol Study, European Health Interview Survey (EHIS), Alcohol Use Disorders Identification Test (AUDIT), etc.

\section{Educational level}

Educational level was assessed using the following question: "what is the highest level of education you have completed to date?' Educational level was defined using four levels: (1) first level, that is, incomplete primary level education, (2) second level, that is, Intermediate, Junior or Group Certificate, or equivalent (complete primary level), (3) third level, that is, leaving Certificate, Diploma or Certificate (complete secondary level) and (4) fourth level, that is, primary degree, postgraduate or higher degree (university level).

\section{Statistical methods}

All statistical analyses took the sample design, that is, the clusters and weights, into account. All variables used in the study were described for both genders and the differences in the distribution of these variables were tested for comparisons between genders using the $\chi^{2}$ Rao-Scott test. The associations between material, psychosocial and behavioural factors and SRH were tested using the $\chi^{2}$ Rao-Scott test. All factors significant at $5 \%$ for at least one gender were kept for multivariate analysis. First, logistic regression models (models 1-3) were used to study the associations between each set of material, psychosocial and behavioural factors separately and SRH, with adjustment for age and educational level (if a factor was not significant for both genders, these models were performed again without this factor). Second, all the factors retained in these first models were included in a final model (model 4) including all material, psychosocial and behavioural factors simultaneously, with adjustment for age and educational level. Although inter-relations between factors were found, no collinearity was detected in all models. Interaction terms were tested between educational level and each material, psychosocial and behavioural factor to detect whether the association between a factor considered and SRH differed according to educational level.

All analyses were performed using the Statistical Analysis System (SAS) separately for men and women, as the prevalence of poor SRH and potential risk factors and the risk factors of poor SRH may differ according to gender.

\section{RESULTS}

Table 1 presents the distribution of all variables in the population studied. The prevalence of poor SRH was $12.14 \%$ for men and $12.10 \%$ for women and there was no difference in this prevalence between genders. Women were more likely to be older and more highly educated. They were more likely to be non-workers and have no car. Women were more likely to be divorced/ separated/widowed and men more likely to be single. The prevalence of no social participation was higher among women than among men, but the prevalence of high social support was higher for women than for men. Men were more likely to have unhealthy behaviours (smoking, alcohol consumption, binge drinking, cannabis and drug use, overweight/obesity and teeth brushing of less than twice a day), but the prevalence of high physical activity was higher for men than for women.

The bivariate associations between material, psychosocial and behavioural factors and SRH are also presented in table 1 . The prevalence of poor SRH increased with older age, lower educational level, nonworking status, no private health insurance, inability to afford enough food and no car for both genders. Home tenure and telephone displayed non-significant associations and were removed from the analysis. The prevalence of poor health increased with separated/ divorced/widowed status, no social participation, neighbourhood problems and low social support for both genders. The prevalence of poor health increased with smoking and exsmoking, no alcohol consumption, no binge drinking, low physical activity, overweight/obesity and infrequent teeth brushing for both genders. Cannabis and drug use were associated with SRH among women only.

Table 2 presents the results from logistic regression analyses, each set of factors being studied separately. As binge drinking, cannabis use and teeth brushing were not significant for both genders, they were not kept in 
Table 1 Description of the population studied and associations between material, psychosocial and behavioural factors and SRH (percentages using sample design and $\chi^{2}$ Rao-Scott test)

\begin{tabular}{|c|c|c|c|c|c|c|c|}
\hline & \multicolumn{3}{|l|}{ Men } & \multicolumn{3}{|c|}{ Women } & \multirow[b]{2}{*}{ p Valuet } \\
\hline & $\mathbf{n}$ & Per cent & $\begin{array}{l}\text { Per cent } \\
\text { of poor SRH }\end{array}$ & $\mathbf{n}$ & Per cent & $\begin{array}{l}\text { Per cent of } \\
\text { poor SRH }\end{array}$ & \\
\hline $\mathrm{SRH}$ & & & & & & & ns \\
\hline Good & 3725 & 87.86 & & 5164 & 87.90 & & \\
\hline Poor & 635 & 12.14 & & 813 & 12.10 & & \\
\hline $30-44$ & 1341 & 32.05 & 7.05 & 1969 & 30.16 & 5.28 & \\
\hline $45-64$ & 1334 & 29.34 & 17.14 & 1844 & 28.81 & 15.27 & \\
\hline $65+$ & 868 & 13.14 & 30.49 & 1101 & 16.03 & 30.31 & \\
\hline Educational level & & & $\star \star \star ~$ & & & $\star \star \star$ & ** \\
\hline First level & 847 & 20.07 & 27.61 & 994 & 19.23 & 30.56 & \\
\hline Work status & & & $* * *$ & & & $\star * *$ & $\star * *$ \\
\hline Working & 2879 & 70.96 & 6.15 & 2983 & 50.89 & 5.33 & \\
\hline Not working & 1467 & 29.04 & 26.71 & 2960 & 49.11 & 19.00 & \\
\hline Private health insurance & & & $\star * *$ & & & $* * *$ & ns \\
\hline Yes & 2302 & 51.16 & 7.91 & 3078 & 49.86 & 7.82 & \\
\hline No & 2009 & 48.84 & 16.17 & 2818 & 50.14 & 15.77 & \\
\hline Afford to buy food & & & $* \star *$ & & & $\star *$ & ns \\
\hline Always & 3597 & 85.37 & 11.08 & 4889 & 84.27 & 11.33 & \\
\hline Usually or less & 550 & 14.63 & 18.42 & 855 & 15.73 & 15.97 & \\
\hline Home tenure & & & ns & & & ns & ns \\
\hline Owned & 3343 & 74.24 & 11.90 & 4524 & 74.06 & 12.20 & \\
\hline Marital status & & & 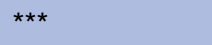 & & & $\star \star \star *$ & $\star \star \star *$ \\
\hline Cohabiting/married & 2433 & 54.91 & 12.02 & 3416 & 52.11 & 12 & \\
\hline Single & 1488 & 38.99 & 10.05 & 1470 & 32.58 & 6.79 & \\
\hline Separated/divorced/widowed & 438 & 6.10 & 26.72 & 1093 & 15.31 & 23.46 & \\
\hline Social participation & & & $\star * *$ & & & 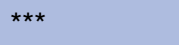 & * \\
\hline Yes & 2564 & 59.82 & 8.47 & 3416 & 56.51 & 9.09 & \\
\hline No & 1732 & 40.18 & 17.88 & 2492 & 43.49 & 15.71 & \\
\hline Neighbourhood problems & & & * & & & * & ns \\
\hline No & 2764 & 64.51 & 11.31 & 3689 & 62.85 & 11.07 & \\
\hline Yes & 1528 & 35.49 & 14.08 & 2217 & 37.15 & 13.38 & \\
\hline Social support & & & $\star \star \star$ & & & ** & $* \star *$ \\
\hline High & 2141 & 48.81 & 11.98 & 3149 & 53.44 & 10.78 & \\
\hline Moderate & 1759 & 41.41 & 10.68 & 2255 & 38.45 & 12.56 & \\
\hline Low & 415 & 9.78 & 19.24 & 508 & 8.11 & 17.61 & \\
\hline \multicolumn{8}{|l|}{ Behavioural factors } \\
\hline Smoking & & & $\star * *$ & & & ** & $* * *$ \\
\hline Non-smoker & 2016 & 46.67 & 8.49 & 3303 & 57.47 & 10.65 & \\
\hline Exsmoker & 1083 & 22.85 & 15.97 & 1076 & 16.10 & 13.27 & \\
\hline Smoker & 1228 & 30.48 & 14.89 & 1565 & 26.43 & 14.51 & \\
\hline
\end{tabular}


Table 1 Continued

\begin{tabular}{|c|c|c|c|c|c|c|c|}
\hline & \multicolumn{3}{|l|}{ Men } & \multicolumn{3}{|c|}{ Women } & \multirow[b]{2}{*}{ p Value } \\
\hline & $\mathbf{n}$ & Per cent & $\begin{array}{l}\text { Per cent } \\
\text { of poor SRH }\end{array}$ & $\mathbf{n}$ & Per cent & $\begin{array}{l}\text { Per cent of } \\
\text { poor SRH }\end{array}$ & \\
\hline Alcohol (drinks/week) & & & $\star \star \star *$ & & & 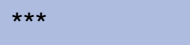 & $\star \star \star *$ \\
\hline $1-7$ & 1128 & 25.96 & 10.12 & 2224 & 36.95 & 8.24 & \\
\hline 0 & 1580 & 34.43 & 17.08 & 2879 & 47.58 & 16.61 & \\
\hline $8-14$ & 846 & 20.37 & 9.34 & 616 & 11.46 & 5.71 & \\
\hline$>14$ & 770 & 19.24 & 9.08 & 210 & 4.01 & 7.43 & \\
\hline Binge drinking & & & $* *$ & & & ** & $* * *$ \\
\hline Less than once a week & 3041 & 67.57 & 13.48 & 5274 & 87.22 & 12.50 & \\
\hline More than once a week & 1277 & 32.43 & 9.31 & 637 & 12.78 & 7.82 & \\
\hline Cannabis & & & ns & & & * & $* * *$ \\
\hline No & 4056 & 92.13 & 12.14 & 5761 & 96.87 & 12.20 & \\
\hline Yes & 262 & 7.87 & 11.43 & 132 & 3.13 & 6.02 & \\
\hline Drugs & & & ns & & & $\star \star \star$ & $\star \star \star *$ \\
\hline No & 4099 & 96.16 & 11.94 & 5671 & 98.19 & 11.54 & \\
\hline Yes & 133 & 3.84 & 17.88 & 106 & 1.81 & 27.97 & \\
\hline Physical activity & & & $\star * \star$ & & & $\star \star \star ~$ & $\star \star \star *$ \\
\hline High & 1325 & 32.33 & 4.82 & 953 & 16.61 & 5.62 & \\
\hline Moderate & 1799 & 41.49 & 11.64 & 3104 & 52.90 & 9.34 & \\
\hline Low & 1154 & 26.18 & 22.54 & 1841 & 30.48 & 19.69 & \\
\hline BMI $\left(\mathrm{kg} / \mathrm{m}^{2}\right)$ & & & $\star \star * *$ & & & $* \star \star$ & $\star \star \star *$ \\
\hline$<25$ & 1687 & 41.92 & 10.81 & 3178 & 58.84 & 9.50 & \\
\hline$\geq 25$ and $<30$ & 1839 & 42.46 & 10.96 & 1632 & 28.24 & 14.15 & \\
\hline$\geq 30$ & 659 & 15.62 & 18.23 & 746 & 12.92 & 18.91 & \\
\hline Teeth brushing & & & 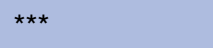 & & & $\star \star \star ~$ & $* * *$ \\
\hline$\geq 2 /$ day & 2462 & 60.93 & 8.53 & 4660 & 80.65 & 9.33 & \\
\hline$<2 /$ day & 1748 & 39.07 & 17.36 & 1122 & 19.35 & 19.84 & \\
\hline
\end{tabular}

the models. All material, psychosocial and behavioural factors were significantly associated with SRH, except inability to afford enough food and marital status for women, and no car for men.

Table 3 presents the final model including all material, psychosocial and behavioural factors together. Poor health was associated with older age, lower educational level, and non-working status for both genders, with no private health insurance and inability to afford enough food for men, and no car for women. Being alone and low social support for men, and neighbourhood problems for women increased the prevalence of poor health. Smoking, no alcohol consumption, low physical activity and overweight/obesity were associated with poor health for both genders, as well as drug use for women. As the analyses of all factors together lead to a reduction in ORs for material factors and especially for psychosocial factors, it is more likely that behavioural factors may be intermediate factors between material and psychosocial factors and SRH.

Table 4 summarises the results for the significant interaction terms found between educational level and factors. Only five significant interactions were observed for inability to afford enough food for men, and for no car, neighbourhood problems, drug use and BMI for women. The interaction between educational level and BMI among women suggested that the association between obesity and SRH was much stronger among high-educated women. The four other interactions showed that the associations with inability to afford enough food for men, and no car, neighbourhood problems and drug use for women were stronger among low-educated people.

\section{DISCUSSION}

Main results

A variety of factors were found to be associated with SRH. Non-working status, absence of private health insurance (for men), inability to afford enough food (for men) and absence of car (for women) were material risk factors of poor SRH. Regarding psychosocial factors, being alone and low social support for men and serious neighbourhood problems for women increased the prevalence of poor SRH. Current and past smoking, use of illicit drugs (for women), low physical activity, 
Table 2 Associations between material (model 1), psychosocial (model 2) and behavioural (model 3) factors and poor SRH: results from logistic regression analysis with each set of factors separately (adjusted for age and educational level) and using sample design

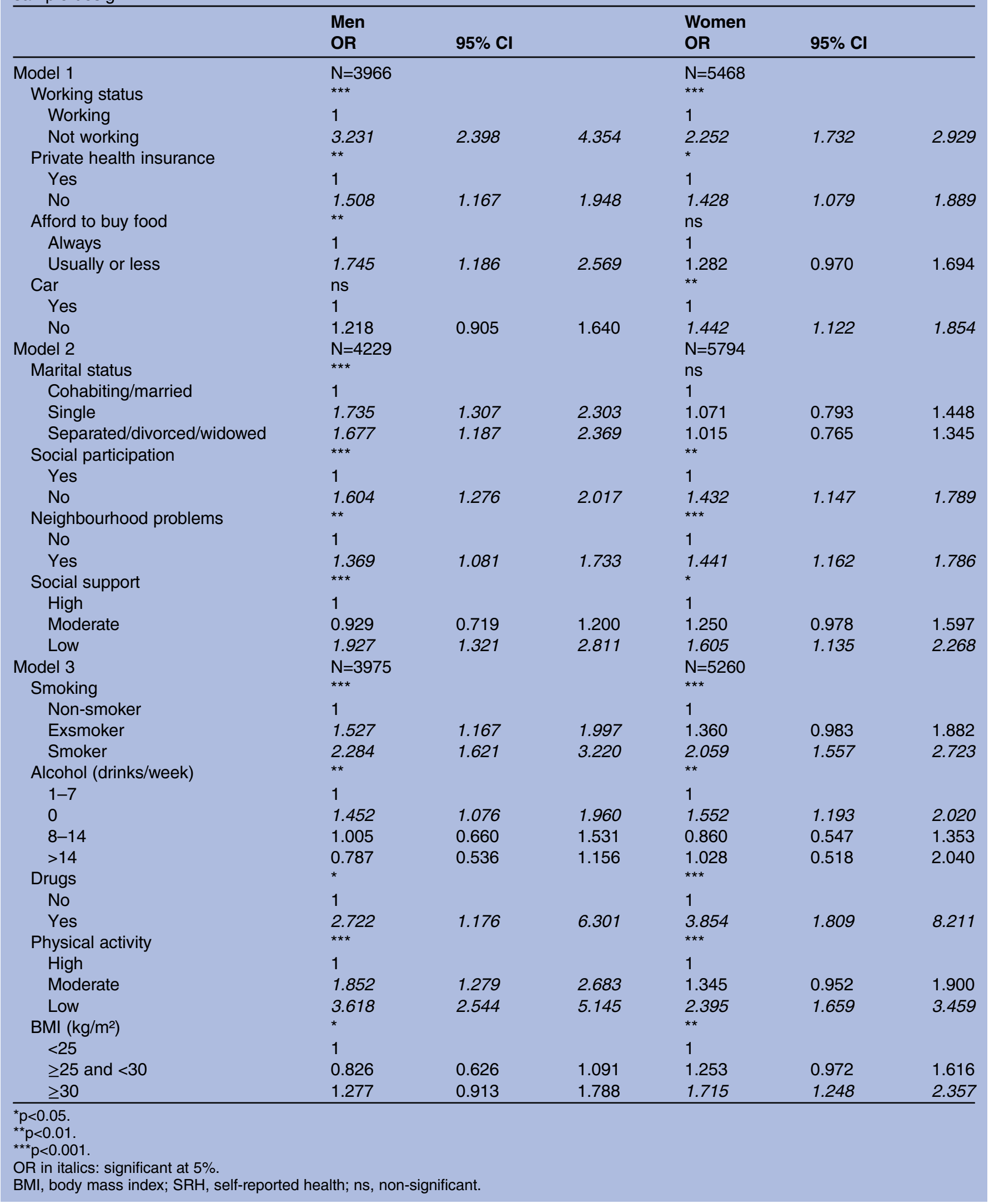


Table 3 Associations between material, psychosocial and behavioural factors (model 4) and poor SRH: results from logistic regression analysis with all sets of factors simultaneously (adjusted for age and educational level) using sample design

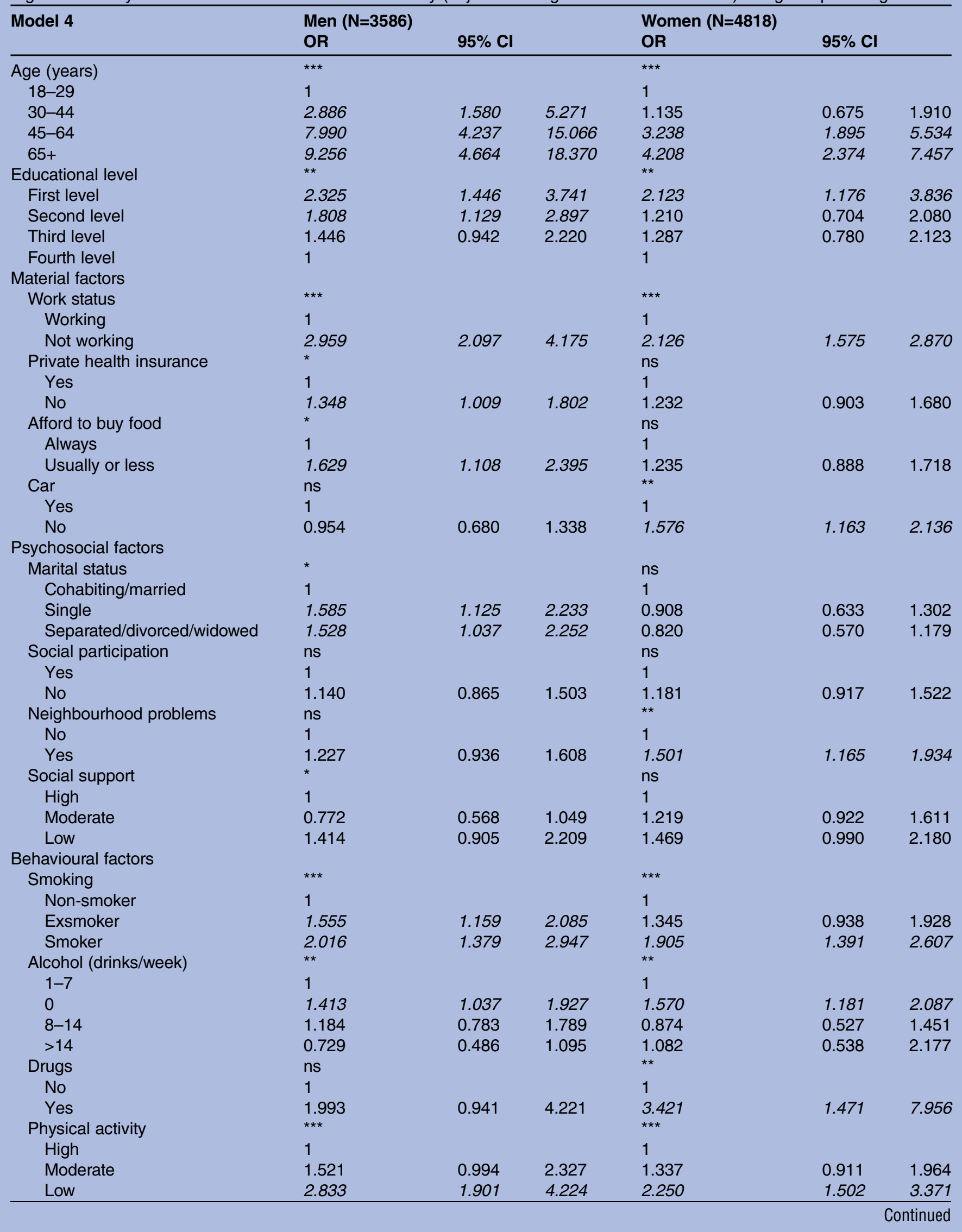




\begin{tabular}{|c|c|c|c|c|c|c|}
\hline Model 4 & OR & \multicolumn{2}{|l|}{$95 \% \mathrm{Cl}$} & OR & \multicolumn{2}{|c|}{$95 \% \mathrm{Cl}$} \\
\hline$<25$ & 1 & & & 1 & & \\
\hline$\geq 25$ and $<30$ & 0.946 & 0.713 & 1.255 & 1.398 & 1.056 & 1.850 \\
\hline$\geq 30$ & 1.539 & 1.087 & 2.178 & 1.787 & 1.274 & 2.507 \\
\hline
\end{tabular}

overweight and obesity, and no alcohol consumption were behavioural risk factors of poor SRH. When material, psychosocial and behavioural factors were studied separately, all these factors, plus low social participation, were significantly associated with SRH and in general for both genders. No difference in the association between these factors and SRH was observed according to educational level, except for obesity that displayed a stronger association among high-educated women and for four factors (inability to afford enough food for men, and no car, neighbourhood problems and drug use for women) that displayed stronger associations among low-educated people. Finally, behavioural factors may be the intermediate factors in the associations between material and psychosocial factors and SRH.

\section{Comparison with literature}

No difference in the crude prevalence of poor SRH was found between genders in our study. Furthermore, no difference in SRH between genders was observed even after adjustment for age and educational level (OR men vs women 1.062; $95 \%$ CI 0.909 to 1.242 ). Other studies showed that the prevalence may be a little higher among women than among men. ${ }^{11} 132122$ The prevalence of poor SRH increased with older age groups, in agreement with other studies. ${ }^{12} 21$ Educational level was strongly associated with SRH; the lower the educational level, the higher was the prevalence of poor SRH, which is completely consistent with previous results ${ }^{10-1321}$ and with a previous analysis in the Republic of Ireland, utilising data from the previous 1998 SLÁN survey. ${ }^{23}$ Social differences in SRH appeared to be stronger among men than among women, but without statistical significance. Other studies found similar results, ${ }^{12}$ or the opposite, ${ }^{10} 13$ or mixed results. ${ }^{11}$

A large number of potential risk factors of poor SRH were studied in our analyses, and covered a large number of important factors as recommended previously. ${ }^{7}$ These factors were classified according to three groups of factors, already used in previous studies. ${ }^{15} 1722$ Although men and women were studied separately, most risk factors were found to be the same for both genders.

Four material factors were observed as risk factors of poor SRH. Non-working status had the strongest association with SRH. Other studies found that nonworking status was associated with poor SRH. ${ }^{24}$ This association may be linked to a selection bias (healthy worker effect), as people in poor health may be more likely to be excluded from the labour market. The other material risk factors were related to economic conditions (absence of private health insurance and inability to afford enough food, both of which may have a direct impact on health) and material living conditions (absence of car). Other studies showed that private health insurance, ${ }^{25}$ economic hardship or problems, ${ }^{21} 22$ car ownership, ${ }^{26}$ and mixed indicators such as deprivation measures including car ownership and housing tenure $^{27}$ were risk factors of SRH.

Four psychosocial factors were associated with SRH in our study, at least in the analyses exploring psychosocial factors separately from material and behavioural factors. Neighbourhood problems were significantly associated with poor SRH among women even in the analyses taking all types of factors into account. Being nonmarried was observed as a risk factor for men, in agreement with previous studies. ${ }^{21} 28$ Social capital measured using trust, social participation and social network resources, ${ }^{29-31}$ and various aspects of the neighbourhood environment ${ }^{31-34}$ and social support ${ }^{21} 2234$ were associated with $\mathrm{SRH}$ in the literature.

Five behavioural factors were associated with SRH in our analyses. The strongest associations were found for low physical activity and smoking for both genders, and drug use for women. Other authors underlined the role of smoking, ${ }^{9}$ no alcohol consumption, ${ }^{9}$ physical inactivity $^{92235}$ and obesity ${ }^{2236}$ in SRH. The unexpected association between no alcohol consumption and poor SRH may at least in part be explained by two phenomena: a selection bias (people in poor health because of alcohol may have stopped drinking) and a reporting bias, leading to an underestimate of alcohol consumption, especially among those with alcohol-related problems. To our knowledge, no previous study has shown an association between use of illicit drugs and SRH in the general population.

The reduction in the ORs associated with material and psychosocial factors, when studied together with behavioural factors, may be explained by an intermediate role of 


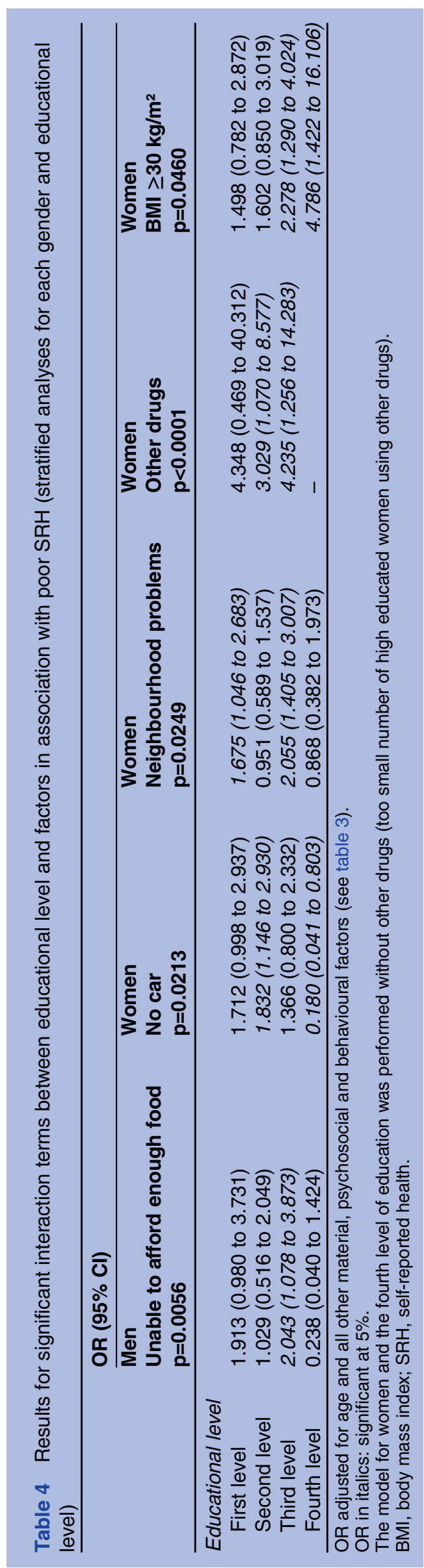

behavioural factors in the association between material and psychosocial factors and SRH. Other authors have suggested similar pathways, such as, for example, Joung et $a \vec{p}^{7}$ showing that behavioural factors may explain a considerable amount of the association between marital status and SRH. As underlined by Mantzavinis et al, ${ }^{7}$ not all candidate risk factors can be dealt with in the same way in multivariate analyses, because some of them may be intermediate steps in the causal pathways to SRH. This is why our final multivariate model (model 4) may underestimate the role of material and psychosocial factors in SRH, and models 1-3 may also be informative.

\section{Strengths and limitations}

The strengths of this study deserve to be mentioned. The study was based on a large representative national sample of the general population in the Republic of Ireland. As our analyses took the sample design of the survey into account, it may be possible to generalise the results for the whole Irish population. As the sample was large enough, it allowed us to study men and women separately, a point that may be crucial given the expected differences between genders regarding health status, and material, psychosocial and behavioural factors. The outcome was SRH, which is a valuable and well-known indicator of health status and a powerful predictor of future morbidity and mortality outcomes. ${ }^{1}{ }^{2} 4-6$ However, studies have suggested that this outcome may lead to an underestimate of the association between social position and SRH, because of a differential reporting of health status according to social position. ${ }^{38}$ A large number of important factors were explored to cover various material, psychosocial and behavioural aspects. These factors were studied using structured multivariate analyses that also included formal interaction testing to explore the differences in the associations according to social position measured by educational level. This point has been examined very rarely in the literature and for outcomes other than SRH. ${ }^{39}{ }^{40}$ Social position was measured using educational level, which is a pertinent variable in the general population. Our analyses were stratified on gender and adjusted for age. Furthermore, additional analyses that took chronic conditions into account suggested that, although somewhat reduced, most of the associations were still significant after adjustment for chronic diseases. Additional analyses were performed with multiple imputation of missing values (multiple imputation by chained equations (MICE) method) and provided similar results (supplementary table 1 ).

The study also has several limitations. As it is crosssectional, no causal conclusions can be drawn. Furthermore, a reverse causation may not be excluded as poor SRH may also have an impact on various material, psychosocial and behavioural factors. The response rate may be considered satisfactory $(62 \%)$, although a participation bias may not be excluded totally, and as the survey is based on a household interview, it excludes institutionalised or homeless people. Nevertheless, as our analyses 
took the sample design (including weights) into account, this potential bias is likely to have no impact on the results. No information was available on the duration of exposure to the factors considered and this may lead to an underestimate of the associations observed. Although the study covered a large number of variables, some may have been neglected. Finally, all variables were self-reported and a reporting bias related to common method variance might have occurred and lead to an overestimate of the associations observed.

\section{Conclusion}

This study showed associations between various material, psychosocial and behavioural factors and SRH. Prevention policies and health promotion should take all the dimensions of these factors into account when planning preventive actions and programmes. Furthermore, as almost all of the associations were found to be similar according to educational level, our results suggest that preventive policies might be oriented to the whole general population for most factors. However, four interaction terms suggested that some factors might have stronger effects on SRH among loweducated people; this point should be confirmed by other studies. Forthcoming prospective studies may also be needed to confirm our results and provide a better understanding of the associations observed.

\author{
Author affiliations \\ ${ }^{1}$ INSERM, U1018, CESP Centre for Research in Epidemiology and Population \\ Health, Epidemiology of Occupational and Social Determinants of Health \\ Team, Villejuif, France \\ ${ }^{2}$ Univ Paris-Sud, UMRS 1018, Villejuif, France \\ ${ }^{3}$ Université de Versailles St-Quentin, UMRS 1018, Villejuif, France \\ ${ }^{4}$ UCD School of Public Health, Physiotherapy and Population Science, \\ University College Dublin, Dublin, Ireland
}

Acknowledgements The authors thank the SLÁN 2007 Consortium, the Health Promotion Unit, and the Irish Social Sciences Data Archives, UCD, especially James McBride, for providing the archived SLÁN dataset used in this study. The authors also thank Emilie Chazelle for her earlier work on the SLÁN survey data and Karen Morgan for providing information about the SLÁN database.

Contributors IN wrote the study protocol, performed the literature review, and wrote the first draft of the manuscript. SK performed the statistical analyses and made contributions to the literature review and interpretation of the results. JFC made contributions to the statistical analyses, as well as to the interpretation of the results and manuscript revisions. SS and CCK made contributions to the interpretation of the results and manuscript revisions. All authors have read and approved the final version of the manuscript.

Funding This research received no specific grant from any funding agency in the public, commercial or not-for-profit sectors.

Competing interests None.

Provenance and peer review Not commissioned; externally peer reviewed.

Data sharing statement No additional data are available.

\section{REFERENCES}

1. Kaplan GA, Goldberg DE, Everson SA, et al. Perceived health status and morbidity and mortality: evidence from the Kuopio ischaemic heart disease risk factor study. Int J Epidemiol 1996;25:259-65.
2. Miilunpalo S, Vuori I, Oja P, et al. Self-rated health status as a health measure: the predictive value of self-reported health status on the use of physician services and on mortality in the working-age population. J Clin Epidemiol 1997;50:517-28.

3. Moller L, Kristensen TS, Hollnagel $\mathrm{H}$. Self rated health as a predictor of coronary heart disease in Copenhagen, Denmark. J Epidemiol Community Health 1996;50:423-8.

4. Idler EL, Benyamini Y. Self-rated health and mortality: a review of twenty-seven community studies. J Health Soc Behav 1997; 38:21-37.

5. Jylha M. What is self-rated health and why does it predict mortality? Towards a unified conceptual model. Soc Sci Med 2009;69:307-16.

6. McGee DL, Liao Y, Cao G, et al. Self-reported health status and mortality in a multiethnic US cohort. Am J Epidemiol 1999;149:41-6.

7. Mantzavinis GD, Pappas N, Dimoliatis ID, et al. Multivariate models of self-reported health often neglected essential candidate determinants and methodological issues. J Clin Epidemiol 2005;58:436-43.

8. Dunn JR, Walker JD, Graham J, et al. Gender differences in the relationship between housing, socioeconomic status, and self-reported health status. Rev Environ Health 2004;19:177-95.

9. Giron P. Determinants of self-rated health in Spain: differences by age groups for adults. Eur J Public Health 2012;22:36-40.

10. Honjo K, Kawakami N, Takeshima T, et al. Social class inequalities in self-rated health and their gender and age group differences in Japan. J Epidemiol 2006;16:223-32.

11. Kunst $A E$, Bos $V$, Lahelma $E$, et al. Trends in socioeconomic inequalities in self-assessed health in 10 European countries. Int $J$ Epidemiol 2005;34:295-305.

12. McFadden $\mathrm{E}$, Luben $\mathrm{R}$, Bingham $\mathrm{S}$, et al. Social inequalities in self-rated health by age: cross-sectional study of 22457 middle-aged men and women. BMC Public Health 2008;8:230.

13. Schutte S, Chastang JF, Parent-Thirion A, et al. Social differences in self-reported health among men and women in 31 countries in Europe. Scand J Public Health 2013;41:51-7.

14. Morgan K, McGee H, Watson D, et al. SLÁN 2007: Survey of Lifestyle, Attitudes \& Nutrition in Ireland. Main report. 2008. Dublin: Department of Health and Children.

15. Chazelle E, Lemogne C, Morgan K, et al. Explanations of educational differences in major depression and generalised anxiety disorder in the Irish population. J Affect Disord 2011; 134:304-14

16. Almirall J, Bolibar I, Serra-Prat M, et al. New evidence of risk factors for community-acquired pneumonia: a population-based study. Eur Respir J 2008;31:1274-84.

17. Aldabe $B$, Anderson R, Lyly-Yrjanainen $\mathrm{M}$, et al. Contribution of material, occupational, and psychosocial factors in the explanation of social inequalities in health in 28 countries in Europe. J Epidemiol Community Health 2011;65:1123-31.

18. Skalicka V, Van Lenthe F, Bambra C, et al. Material, psychosocial, behavioural and biomedical factors in the explanation of relative socio-economic inequalities in mortality: evidence from the HUNT study. Int J Epidemiol 2009;38:1272-84.

19. van Oort FV, van Lenthe FJ, Mackenbach JP. Material, psychosocial, and behavioural factors in the explanation of educational inequalities in mortality in The Netherlands. J Epidemiol Community Health 2005;59:214-20.

20. Meltzer $\mathrm{H}$. Development of a common instrument for mental health. In: Nosikov A, Gudex C, eds. EUROHIS: Developing Common Instruments for Health Surveys. Work Health Organization Regional Office for Europe, IOS Press, 2003, 35-60.

21. Lindstrom M. Marital status, social capital, material conditions and self-rated health: a population-based study. Health Policy 2009;93:172-9.

22. Molarius A, Berglund K, Eriksson C, et al. Socioeconomic conditions, lifestyle factors, and self-rated health among men and women in Sweden. Eur J Public Health 2007;17:125-33.

23. Kelleher CC, Friel S, Nic GS, et al. Socio-demographic predictors of self-rated health in the Republic of Ireland: findings from the National Survey on Lifestyle, Attitudes and Nutrition, SLAN. Soc Sci Med 2003;57:477-86.

24. Popham F, Gray L, Bambra C. Employment status and the prevalence of poor self-rated health. Findings from UK individual-level repeated cross-sectional data from 1978 to 2004 BMJ Open 2012;2:e001342.

25. Hullegie $P$, Klein TJ. The effect of private health insurance on medical care utilization and self-assessed health in Germany. Health Econ 2010;19:1048-62.

26. Monden $\mathrm{CW}$. Changing social variations in self-assessed health in times of transition? The Baltic States 1994-1999. Eur J Public Health 2005;15:498-503. 
27. White IR, Blane D, Morris JN, et al. Educational attainment, deprivation-affluence and self reported health in Britain: a cross sectional study. J Epidemiol Community Health 1999;53:535-41.

28. Joutsenniemi KE, Martelin TP, Koskinen SV, et al. Official marital status, cohabiting, and self-rated health-time trends in Finland, 1978-2001. Eur J Public Health 2006;16:476-83.

29. Giordano GN, Lindstrom M. The impact of changes in different aspects of social capital and material conditions on self-rated health over time: a longitudinal cohort study. Soc Sci Med 2010;70:700-10.

30. Nieminen T, Martelin T, Koskinen S, et al. Social capital as a determinant of self-rated health and psychological well-being. Int $J$ Public Health 2010;55:531-42.

31. Verhaeghe PP, Tampubolon G. Individual social capital, neighbourhood deprivation, and self-rated health in England. Soc Sci Med 2012;75:349-57.

32. Agyemang C, van HC, Wendel-Vos W, et al. The association of neighbourhood psychosocial stressors and self-rated health in Amsterdam, The Netherlands. J Epidemiol Community Health 2007;61:1042-9.

33. Cummins S, Stafford M, Macintyre S, et al. Neighbourhood environment and its association with self rated health: evidence from Scotland and England. J Epidemiol Community Health 2005;59:207-13.

34. Linden-Bostrom M, Persson C, Eriksson C. Neighbourhood characteristics, social capital and self-rated health-a population-based survey in Sweden. BMC Public Health 2010;10:628.

35. Sodergren M, Sundquist J, Johansson SE, et al. Physical activity, exercise and self-rated health: a population-based study from Sweden. BMC Public Health 2008;8:352.

36. Imai K, Gregg EW, Chen YJ, et al. The association of BMI with functional status and self-rated health in US adults. Obesity (Silver Spring) 2008;16:402-8.

37. Joung IM, Stronks $\mathrm{K}$, van de $\mathrm{MH}$, et al. Health behaviours explain part of the differences in self reported health associated with partner/ marital status in The Netherlands. J Epidemiol Community Health 1995;49:482-8.

38. Delpierre C, Lauwers-Cances V, Datta GD, et al. Using self-rated health for analysing social inequalities in health: a risk for underestimating the gap between socioeconomic groups? $J$ Epidemiol Community Health 2009;63:426-32.

39. Cohidon C, Santin G, Imbernon E, et al. Working conditions and depressive symptoms in the 2003 decennial health survey: the role of the occupational category. Soc Psychiatry Psychiatr Epidemiol 2010;45:1135-47.

40. Griffin JM, Fuhrer R, Stansfeld SA, et al. The importance of low control at work and home on depression and anxiety: do these effects vary by gender and social class? Soc Sci Med 2002;54:783-98. 